\title{
Editorial
}

\section{Bienvenue au Dernier-né}

Journals, creatures of society, mimic many of its natural and man-made laws. Some die, or "cease publication" as Current Contents more delicately puts it. Some choose to live together, as did Micron and Microscopica Acta in 1983, though 1995 sees Microscopica Acta banished from the title. Some unite but give way to their offspring - thus was Europhysics Letters born. And of course, new titles are born. The first number of the Journal of the [formerly Electron] Microscopy Society of America (not to be confused with the Transaction of the American Microscopical Society, which is a completely different affair) has just appeared and old hands like ourselves, already into our third title, wish it many manuscripts (preferably on themes other than those welcomed by MMM) and a healthy citation index (ours is 1.02 and rising steadily).

What does No. 1 have to offer? Four articles, which emphasize the disappearance of the "E" from EMSA, since there is no electron microscopy at all! Instead, we find confocal ratio imaging, fluorescence microscopy, two-photon excitation microscopy and vibrational spectroscopic microscopy. Was this what the members expected when they voted to change from EMSA to MSA? There is also "MSA News and Commentary", which begins with an editorial by Jean-Paul Revel (JMSA = "J'aime ça") and includes Prognostications (by P. Ingram, Albert Crewe, Joachim Frank, Richard Leapman, C. Lyman, J.D. Robertson, A.P. Somlyo, David Williams, R. Linton and Elmar Zeitler). It concludes with the most original feature of the whole issue, a list compiled by Caroline Schooley of Children's Books on Microscopy, which spills over NINE pages. The authors of such books allow themselves much more latitude than we are accustomed to in the matter of titles. Thus $\mathrm{K}$. Ruef's "manual that shows how to use a 5x jeweler's loupe to incorporate constructivist science into an integrated curriculum over the full K-12 grade range" is entitled The Private Eye; D. Zook and "the Microcosmos Team" call theirs The Microcosmos Guide to Exploring Microbial Space.

Actually, that is not the most original feature of the issue, for either the publisher or the editor has had the extraordinary idea of adopting two sets of page numbers. Advertisements apart, the issue opens with 19 italic-numbered pages (1-19); then we have 46 roman-numbered pages (1-46); the italic numbering is then resumed (22-45). If other kinds of material are to be included in future, we shall no doubt have bold-face, script and all the other variants available on the word-processor, and references to the journal may read:

J.-P. Revel, J. Microsc. Soc. Am. 1 (1995) 1-5.

R. Carpenter, J. Microsc. Soc. Am. 1 (1995) 1-5.

J. Bentley, J. Microsc. Soc. Am. 1 (1995) 1-5.

C. Bustamente, J. Microsc. Soc. Am. 1 (1995) 1-5.

etc. It will be interesting to see whether the page numbering begins again at $1(1,1,1, \ldots)$ in each issue.

JMSA is free to members of the Microscopy Society of America. American libraries will have to pay \$250, others \$297.70; enquiries to Jones and Begell, Suite 1201, 79 Madison Avenue, New York, NY 10016, U.S.A. The ISSN is 1079-8501. 